\title{
A HIERARCHICAL CONSTRAINT-BASED APPROACH TO MODELING CONSTRUCTION AND MANUFACTURING PROCESSES
}

\author{
Ian Flood \\ Rinker School, College of Design Construction and Planning, \\ University of Florida, \\ Gainesville, FL 32611, USA
}

\begin{abstract}
Modeling construction processes is an essential part of project planning and control. Most modeling exercises use the Critical Path Method (CPM) since it is simple to use and versatile. Almost all other modeling techniques are aimed at specialized types of construction work, such as linear scheduling which is used for modeling work that progresses along a line. Discreteevent simulation has also been used for construction modeling, and while it is extremely versatile, it lacks the simplicity in use of CPM and so has not been widely adopted within the industry. This paper goes back to first principles, identifying the needs of construction project planning and how existing tools meet (or fail to meet) these requirements. Based on this, a new modeling paradigm is proposed that is better suited to the needs of contemporary construction project planning. The principles of the method are demonstrated in application to three example construction projects.
\end{abstract}

\section{INTRODUCTION}

The last 100 years have seen the development of a wide range of tools for construction process modeling. An analysis of the genealogy of these tools (Flood et al. 2006) indicates that they fall into three main categories (the Critical Path Methods (CPM), linear scheduling techniques, and simulation), with most other tools either enhancements or an integration of these techniques. Even 4D-CAD and nD-CAD methods (see, for example, Koo and Fischer 2000, Issa et al. 2003), where one of the dimensions is time, are strictly CPM models hybridized with 3D-CAD for visualization purposes.

Each of these categories of modeling tool are, unfortunately, only relevant to a restricted class of construction planning problems. CPM, the most popular modeling method, is well suited to planning projects at a relatively general level of detail. However, when applied to repetitive work, CPM models are unduly complicated and provide little understanding of the interactions between repetitive tasks. In addition, they are limited in terms of the types of interactions they can consider between tasks (see, for example, Harris and Ioannou 1998). Linear scheduling, on the other hand, is targeted at projects where there is repetition at a high level, such as tunnel, highway, and high-rise construction work (see, for example, Matilla and Abraham 1998). These models are very easy to understand and provide great insight into the behavior of a construction system, but they cannot be used at all to model non-repetitive work and include some simplistic assumptions which often make it difficult to model real-world repetitive work. For example, velocity diagrams (a linear scheduling technique) cannot easily represent operations that follow different paths, such as two underground utility lines that interact at a cross-over point but otherwise follow different routes. Finally, simulation (see, for example, Halpin and Woodhead 1976, Sawhney et al. 1998, Hajjar and AbouRizk 2002) is very versatile in that it can in principle model any type of construction project (including repetitive and non-repetitive tasks) and any type of interaction between tasks. However, the work involved in defining and validating a simulation model means that in practical terms it is best suited to systems that cannot otherwise be represented accurately using CPM or linear scheduling.

What is missing is a single tool that is well suited to modeling the broad spectrum of repetitive and non-repetitive construction work, that is versatile, provides insight into better ways of completing work, and is easy to use. Currently planners are left with two options: (i) to use a selection of process modeling tools or; (ii) to adopt a compromise by using a single tool for modeling all types of work, even though it will not be ideal for many situations. The first choice is rarely adopted since it requires the planner, and all other involved parties, to be proficient in the use of several software packages; moreover, the output from multiple tools cannot be readily integrated into a single analysis. Typically CPM is the choice of compromise. 
This paper goes back to basics and proposes a new modeling paradigm that addresses all of the above issues. The new approach is first outlined and then demonstrated in application to three construction projects that would otherwise be modeled using linear scheduling, CPM, and simulation, respectively.

\section{PRINCIPLES OF THE NEW MODELING APPROACH}

The goal in developing the new approach to modeling was to attain the simplicity of CPM, visual insight of linear scheduling, and the modeling versatility of simulation. In addition, hierarchical structuring and interactive development of a model were identified as requisite attributes of the new approach since, in other fields of computation, they have been shown to facilitate an enhanced understanding of the organization and behavior of a system. The proposed new approach to modeling construction processes is shown schematically in Figure 1, and comprises the following three primary elements:

1. Resource Space. This is the environment within which the model of the construction process exists. Each dimension defining this space represents a different resource that is used in the execution of the construction process, such as time, money, excavators, skilled labor, permits to perform work, and materials. All dimensions within this space are considered to operate orthogonally. The resources that should make-up this space are those that need to have their usage monitored, could have a direct impact on the performance of the construction process, and/or provide a good means of measuring the performance of the process.

2. Work Units. These are elements that exist within the resource space and represent specific items of work that need to be completed as part of the project. A unit can represent work at a high level (such as 'Construct Structural System' at a low level (such as 'Erect Column $X$ ') or at any intermediate level. Collectively, the work units should represent all work of interest but should not represent any item of work more than once. Most if not all work units will exist in a subset of the dimensions of the resource space, although normally they will all exist at least within the time dimension. A work unit could in principle take on any form, but for the purposes of this paper they will be limited to rectangular shapes (or hyper-rectangular shapes in the case that they exist within more than 2 dimensions of the resource space) the use of the rectangular form simplifies the structure and definition of these models and provides sufficient flexibility to model the broad range of construction processes.

3. Constraints and Objectives. Constraints define the relationships between the work units and the resource space, either directly with the resource space or indirectly via relationships with other work units. These constraints effectively define the position of the edges of the rectangles/hyper-rectangles. A constraint can be any functional relationship between the edges of the rectangles and or the space within which they exist. Practical examples would be to ensure that crews maintain a safe working distance, the demand for resources never exceeds the availability, and that idle time for a task is kept to a minimum. In addition, the length of any side of a box can be functionally related to the length of any of its other sides. The objectives are the specific goals of the planning study, such as to maximize profits or to complete work by the contract deadline. Fundamentally, they are the same thing as constraints, albeit at a higher level of significance, and therefore are treated as such within the proposed new system.

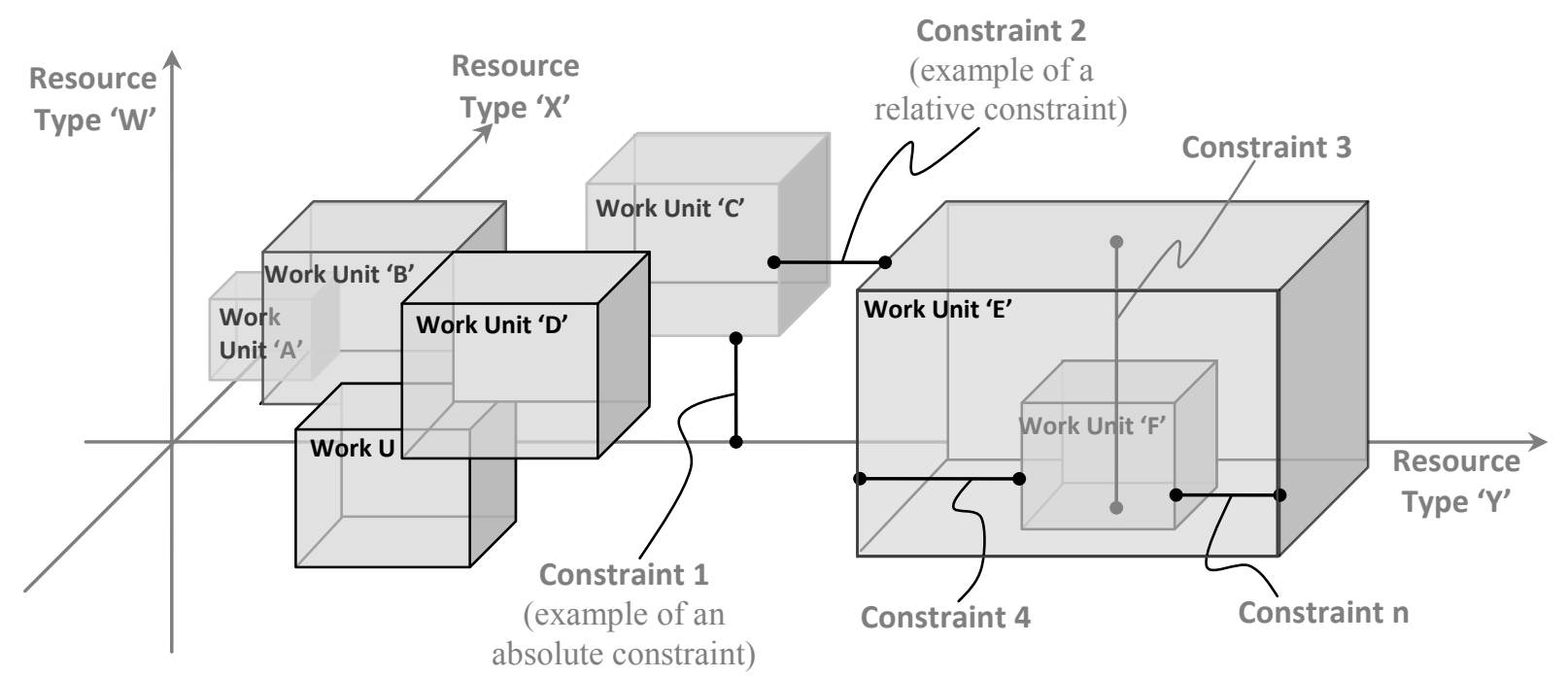

Figure 1: The Three Primary Elements of the New Modeling System 
Note that work units can by implication be nested within other work units (such as Work Unit 'F' which is shown to be within Work Unit 'E' in Figure 1), or overlap with each other (such as Work Units 'A' and 'B'). Although the approach does not impose nesting explicitly (since there are modeling situations where it would be too inflexible), it is recommended that development of a model is based as far as possible on a hierarchical nested structure. This has the advantages of allowing the model to be understood at different levels of abstraction, increases its readability, reduces the likelihood of errors in the design of the model, and reduces the amount of work required to define and update a model.

A specification of the new modeling approach is that model development be implemented interactively. That is, the visual presentation of the model is updated and all constraints are resolved as the work units and constraints are either edited or added to the model. This way, the user can see immediately the impact of any changes or additions that are made. Another point to note is that these models are presented as a plot of the work units within at least two dimensions of the resource space. This form of presentation allows the progress of work to be visualized within the model's functional structure. This is an extrapolation of the way in which linear scheduling models are presented, and has the advantage of allowing the user to visualize directly how the performance of the model is dependent on its structure. These points will be illustrated in the following three example applications.

\section{UNDERGROUND ELECTRICAL CABLE PROJECT}

This first example demonstrates the application of the new approach to the modeling of an underground electrical cable project that is highly repetitive in nature and would normally be best modeled using linear scheduling techniques. Figure 2 is a sketch of the run of the underground electrical cable, showing how its depth below grade varies across its length. The project is broken down into four second level work units: Excavate trench; Shore trench; Lay cable; and Backfill. Figure 3 shows these work units contained within the higher level work unit Underground electrical cable. The figure is plotted within a two dimensional resource space: length of the cable run (horizontal axis) and time (vertical axis). Constraints between these work units are indicated by the links. The constraints shown to the left of the figure specify that the four lower level work units must each physically start at the beginning of the Underground electrical cable run. The constraints to the right of Figure 3 indicate that the lower level units must progress all the way to the end of the Underground electrical cable run. The highest level work unit, Underground electrical cable, has its start and finish positions constrained to the absolute values $0 \mathrm{~m}$ and $70 \mathrm{~m}$.

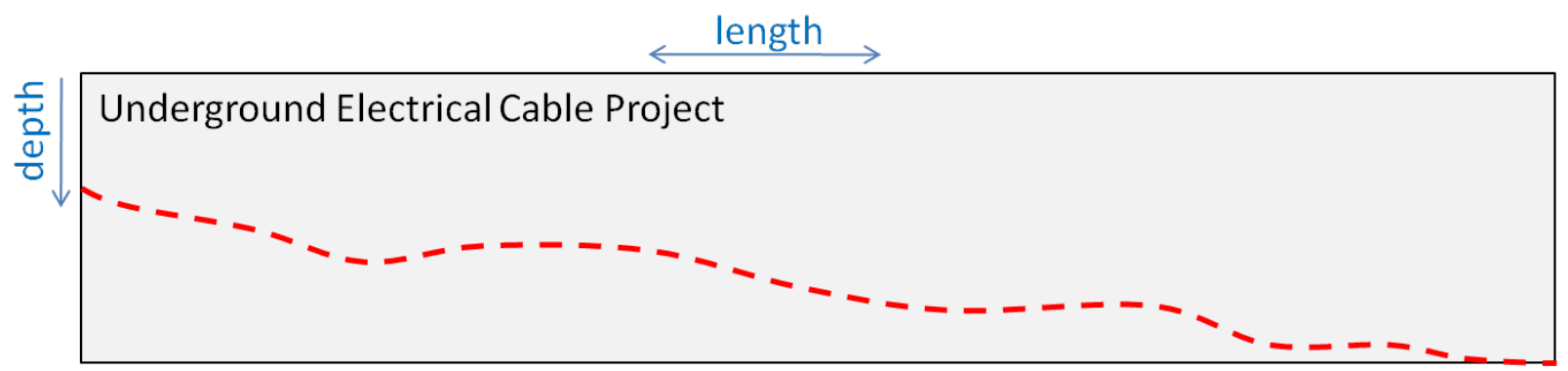

Figure 2: Underground Electrical Cable Run, Depth versus Length of Cable

Figure 4 shows the addition of three third level work units that represent the work of the trench excavation crews. For this project, there are two crews available and one is known to operate faster than the other. Several strategies could be attempted to employ these crews as efficiently as possible; in this example the strategy adopted is to start the fast crew at the $0 \mathrm{~m}$ station of the cable run and to start the slow crew at the $34 \mathrm{~m}$ station. The strategy is then to allow the fast crew to work up to the $34 \mathrm{~m}$ station at which point they jump to where the slow crew are currently located and continue working from there towards the end of the cable run - this is represented by a second work unit for the fast crew shown to the right of the figure. The constraints in the length dimension required to implement this logic are given by the links connecting to the left and right edges of the boxes. Note, many of these constraints are absolute, referring to specific positions along the length of the cable run (such as $0 \mathrm{~m}, 34 \mathrm{~m}$, and $70 \mathrm{~m}$ ). However, the second incident of Fast exc. crew includes a relative constraint in that it connects to the right edge of the work unit Slow exc. crew. Also, the finish point of the first incident of Fast exc. crew is shown relative to the start of Slow exc. crew - this is done so that if the starting position of Slow exc. crew is changed then the finish position of the Fast exc. crew will automatically change to match it. This will facilitate optimizing the plan later in the study. 


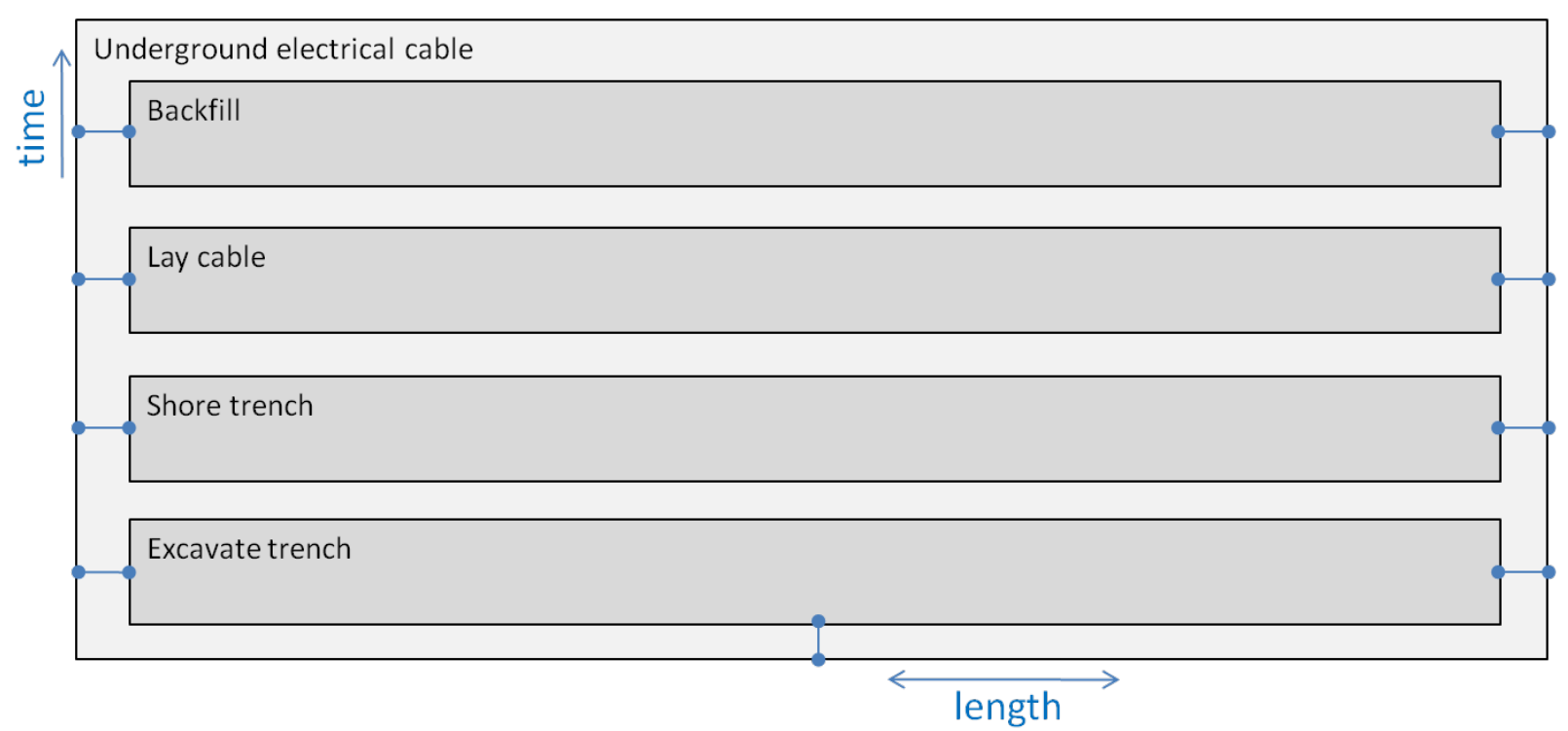

Figure 3: Addition of the Main Work Units and Constraints of the Pipeline Project

The constraints in the time dimension in Figure 4 (shown by the links connecting the top and bottom edges of the boxes) show that the first incident of Fast exc. crew starts when the project starts. Similarly, the work unit Slow exc. crew also starts when the project starts. Finally, since there is only one crew that operates at the fast rate, the second incident of Fast exc. crew is constrained to start only after the first incident has finished.

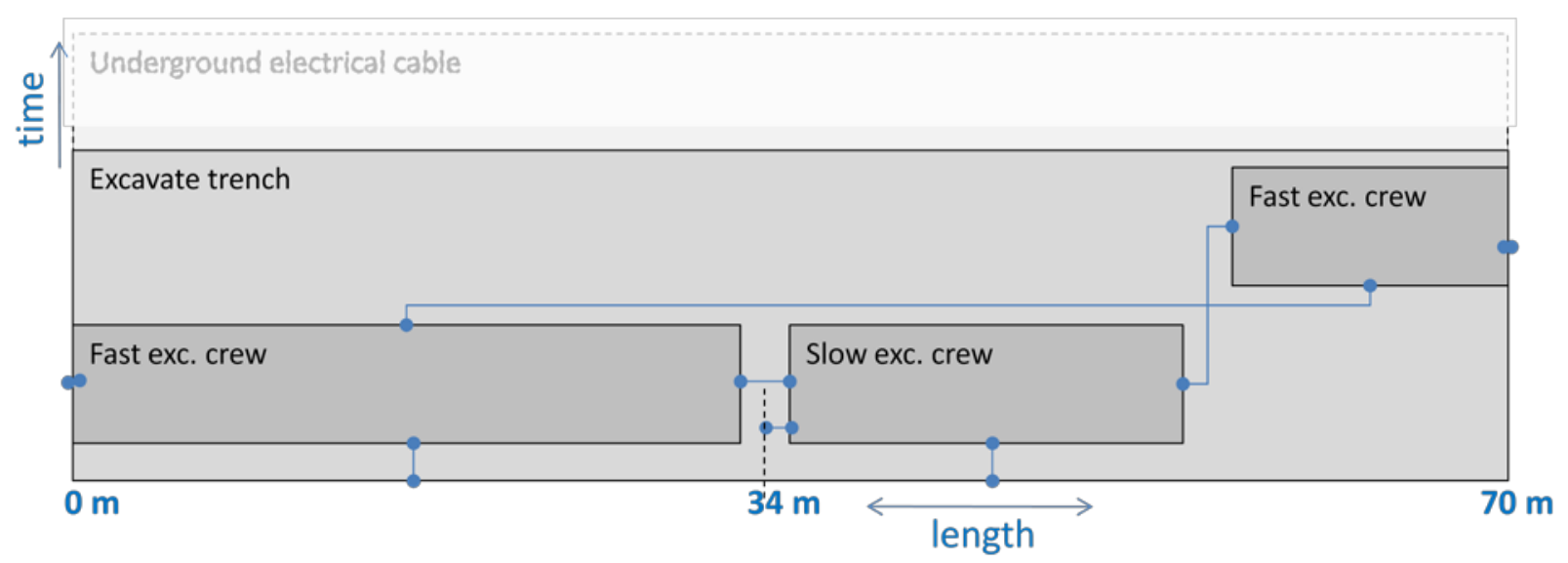

Figure 4: Addition of the Work Units and Constraints of the Trench Excavation Crews

Figure 5 shows the further breakdown of trench excavation into $1 \mathrm{~m}$ length work units, represented by the small boxes in the figure. Only three such work unit needs to be defined, one for each of the two incidents of Fast exc. crew and one for Slow exc. crew. These work units will then be replicated as many times as possible within the constraints imposed upon them. For example, one set of constraints for these $1 \mathrm{~m}$ length work units would say that their leading edges follow the trailing edges of the preceding $1 \mathrm{~m}$ work unit, both in the time and length dimensions; in other words they stack both vertically and horizontally. Another set of constraints will require that they fall within the boundaries of their parent work units: Slow exc. crew or either incident of Fast exc. crew. Figure 5 shows the situation after these constraints have been resolved, so the positions of the edges of all boxes shows both when (in the time dimension) and where (in the length dimension) the work units are expected to start and finish.

The length of these work units in the time dimension represents the duration required to excavate that $1 \mathrm{~m}$ section of the trench, and would be determined by a constraint that defines the distance of its top edge form its bottom edge. These durations vary with the depth of the trench at that location. For this purpose, the $1 \mathrm{~m}$ length work units would also exist in a third 
dimension representing trench depth (see Figure 2). The length of a $1 \mathrm{~m}$ work unit in the time dimension would be given by a functional relationship with its length in the depth dimension.

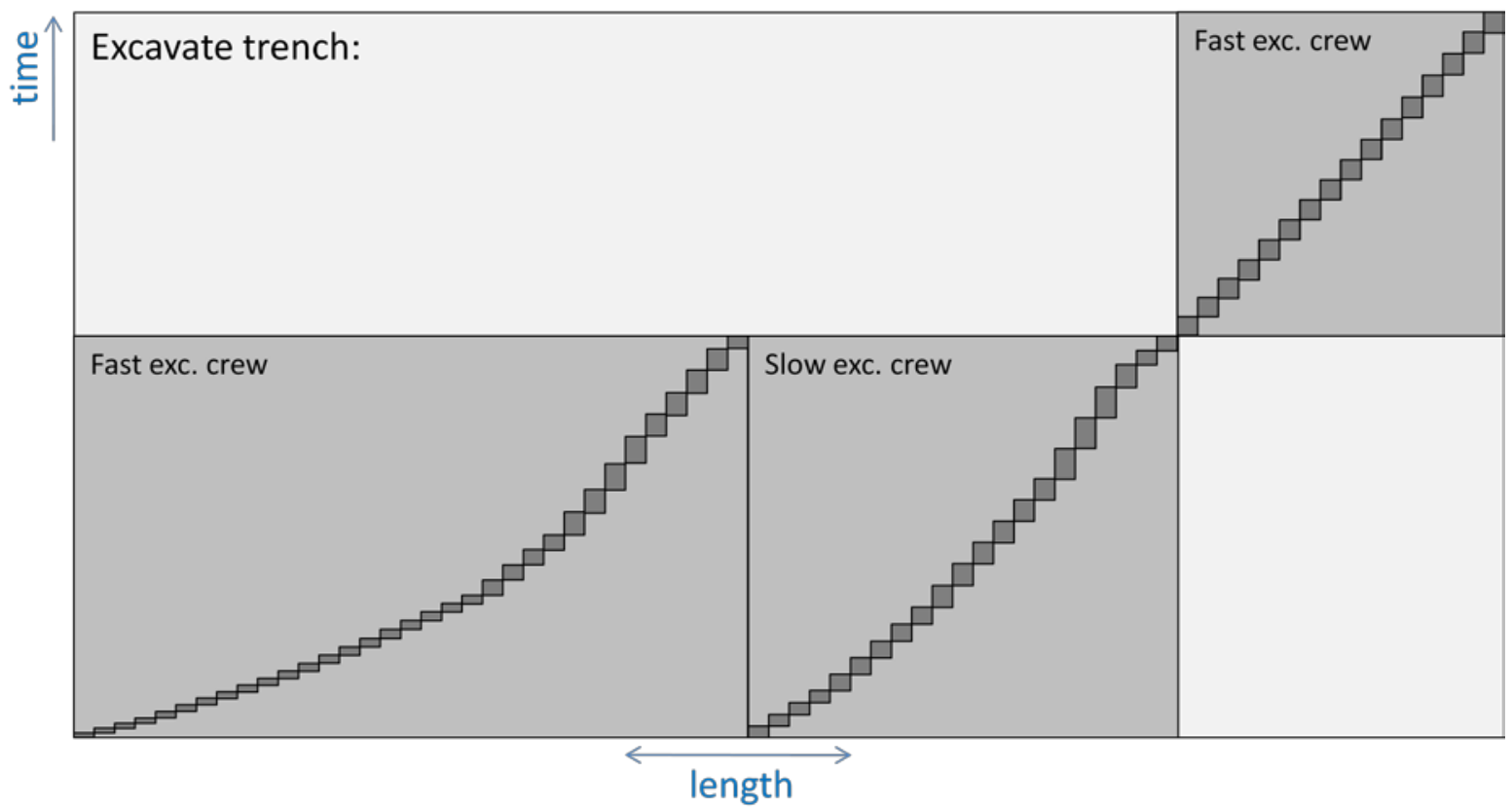

Figure 5: Addition of the Work Units for Excavation of Each Meter length of Trench, with the Constraints Resolved

Figure 6 shows the addition of the work units Shore trench, Lay cable and Backfill, along with their constituent work units. Note, all three of these work units are broken down into $1 \mathrm{~m}$ lengths as indicated by the smallest boxes, and the work in Shore trench is divided between two crews. This figure shows some constraints between the second level work units. The first of these stipulates that Shore trench must be at least $3 \mathrm{~m}$ behind Excavate trench (for safety reasons) but no more than $5 \mathrm{~m}$ behind it (to minimize the chances of the trench collapsing). The other constraints stipulate that Lay cable must be at least $10 \mathrm{~m}$ behind Shore trench, and Backfill must be at least $10 \mathrm{~m}$ behind Lay cable. Resolving these constraints results in the schedule shown in Figure 7. It can be seen from this figure that the crews shoring the trench must spend time idle in order to satisfy their constraints, as indicated by the gaps between the work units shown in blue.

Work units may have some freedom to slide in any direction within the resource space without violating any of the constraints of the model. The extent to which a work unit can slide in the time dimension without causing the end of Underground electrical cable to be pushed back is the equivalent of what is termed Total Float in CPM terminology. Similarly, the extent to which a work unit may slide in the time dimension without pushing back any other succeeding work unit is termed Free Float. The concept of float can be extended beyond that of CPM to measure freedom of movement between any two work units; for example, float could be measured between any $1 \mathrm{~m}$ length of Shore trench and the higher level work unit of the second incident of Fast exc. crew. From this type of analysis it is also possible to identify the critical paths in the project. Moreover, these concepts can be extended to any dimension in the model, beyond time. For some variables, such as the number of key resources used on site, this can be a powerful device for helping understand and optimize the plan.

Once the model has been set-up as shown in Figure 7, it can be used to help satisfy the project objectives. The highly visual nature of these models (which shows both the model structure and its progress within one framework) helps suggest more optimal solutions and the consequences of changing certain parameters in the model. This is a benefit that CPM and simulation models do not provide. This ability combined with the interactive feature of the modeling system, provide a powerful mechanism for optimizing the project objectives. For example, referring to Figure 7, the planner may try dragging the start location of Slow exc. crew to the left or right of its current position of $34 \mathrm{~m}$ to see how this impacts overall project duration. Another strategy the planner might try is to start Slow exc. crew at the end of the cable run (the right side of the figure) working back towards Fast exc. crew. This way, the two crews would meet somewhere in the middle of the cable run and there would be no need for the faster crew to leap-frog the slower crew. A feel for whether this may be more effective can be gained by inspecting the existing model shown in Figure 7. 


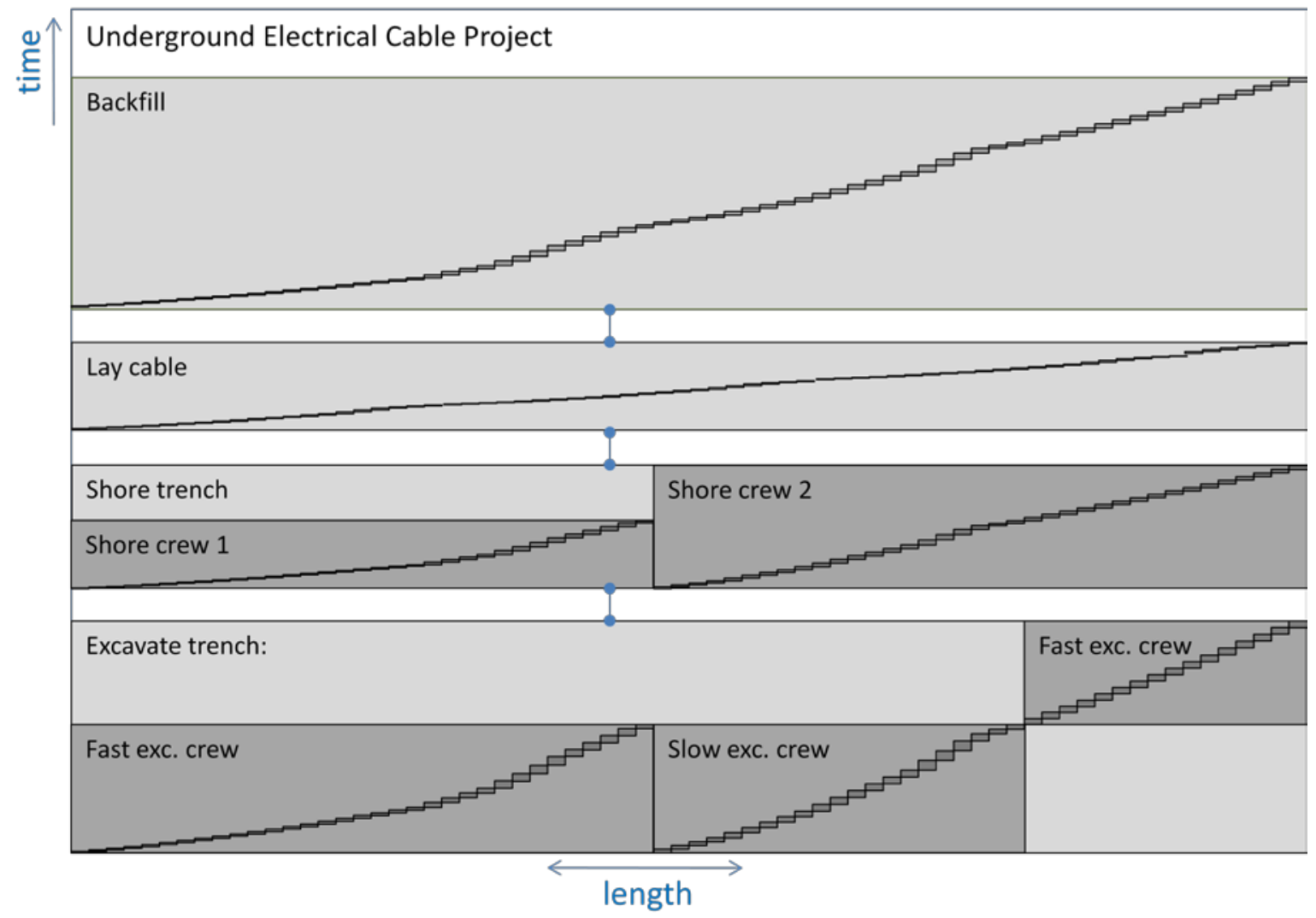

Figure 6: Addition of the Remaining Work Units and Constraints

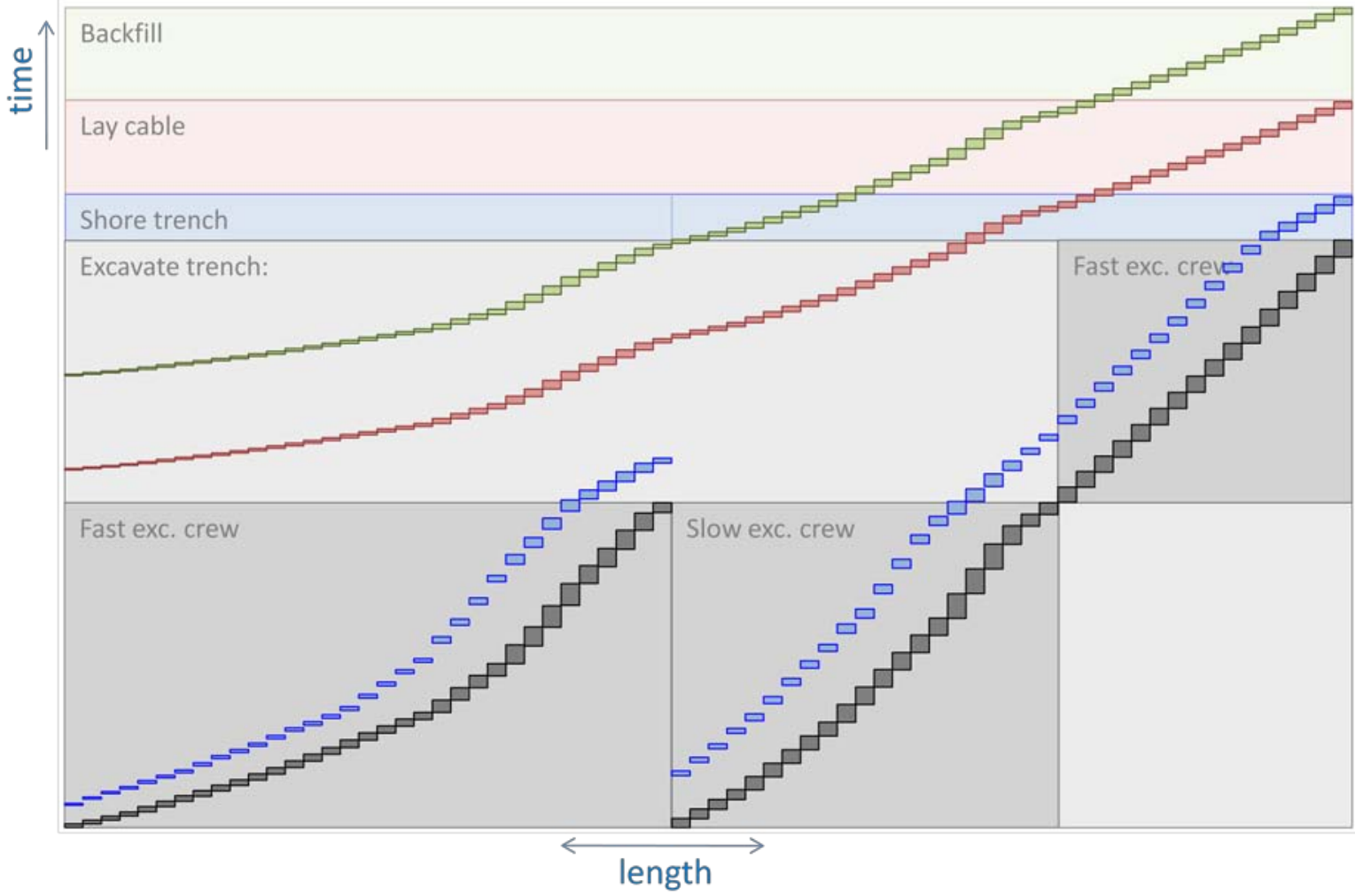

Figure 7: All Work Units with all Constraints Resolved 


\section{BUS STOP CONSTRUCTION PROJECT}

The second example illustrates the application of the approach to the construction of a Bus Stop, which involves nonrepetitive construction work, and is typical of the type of project that would be modeled using the Critical Path Method (CPM). Figure 8 shows the result of breaking down the project into a hierarchy of work units (in this case operating within the time and direct-costs dimensions) and with all constraints resolved. This model, as with any developed using this new approach, can be used conveniently to predict expected progress and monitor actual progress of work, functions crucial to effective project planning. Moreover, unlike conventional CPM, this can be done at any level within the structure of the model.

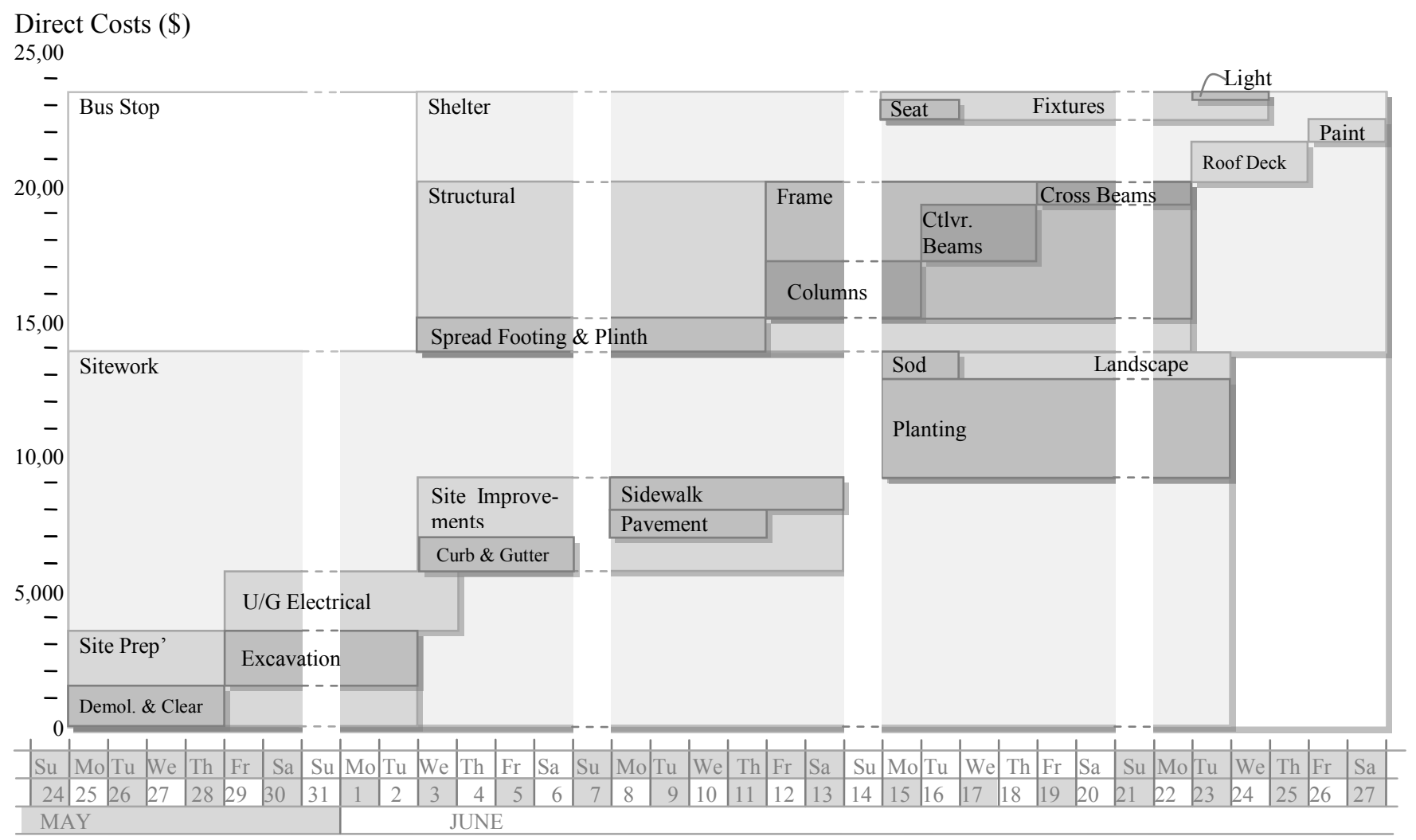

Figure 8: Bus Stop Project with Work Units Shown in the Direct-Cost and Time Dimension

Figure 9, for example, shows projected progress for the Bus Stop project at the third level in the models hierarchy. Projected progress is indicated by the lines which measure (in this case as direct costs $(\$)$ ) the amount of a work unit expected to be completed at any given time. These curves can be used to gain insight into the expected progress of the project, and provide a template against which to measure actual progress on site. Progress curves are generated by the model by tracing the accumulation of work completed by work units over time. Consider the work unit Structural shown in Figure 9. This represents about $\$ 6,000$ in direct costs, made up from the direct costs of its constituent work units, and follows a classic $S$ curve in form.

Progress curves could have been plotted at any level in the model's hierarchy from the highest to the lowest levels. Progress curves at a higher level are good for gaining an understanding of the general rate of progress of the model. In the case of direct costs, this would be useful for determining, among other things, an appropriate line-of-credit required to finance the project. In contrast, progress curves plotted at the lowest level in the project are good for analyzing the likely continuation and impact of any delays to the actual progress of work on site, and for determining what effort is required to bring the project back on target in such events.

\section{EXCAVATION SYSTEM}

The third and final example demonstrates the application of the new approach to modeling an excavation process which is highly repetitive in nature and would normally best be analyzed using simulation methods. Figure 10 shows the breakdown 
of the project into the primary work units and their constraints. Note that in this case, although the model is strongly hierarchical in form, the second level work units Truck cycle and Excavator cycle do not follow a strict hierarchy. That is, they are neither exclusive of each other nor nested within one or other, but rather overlap each other. The overlap represents the section of the work that both the excavator and the trucks perform together, where the excavator loads the truck.

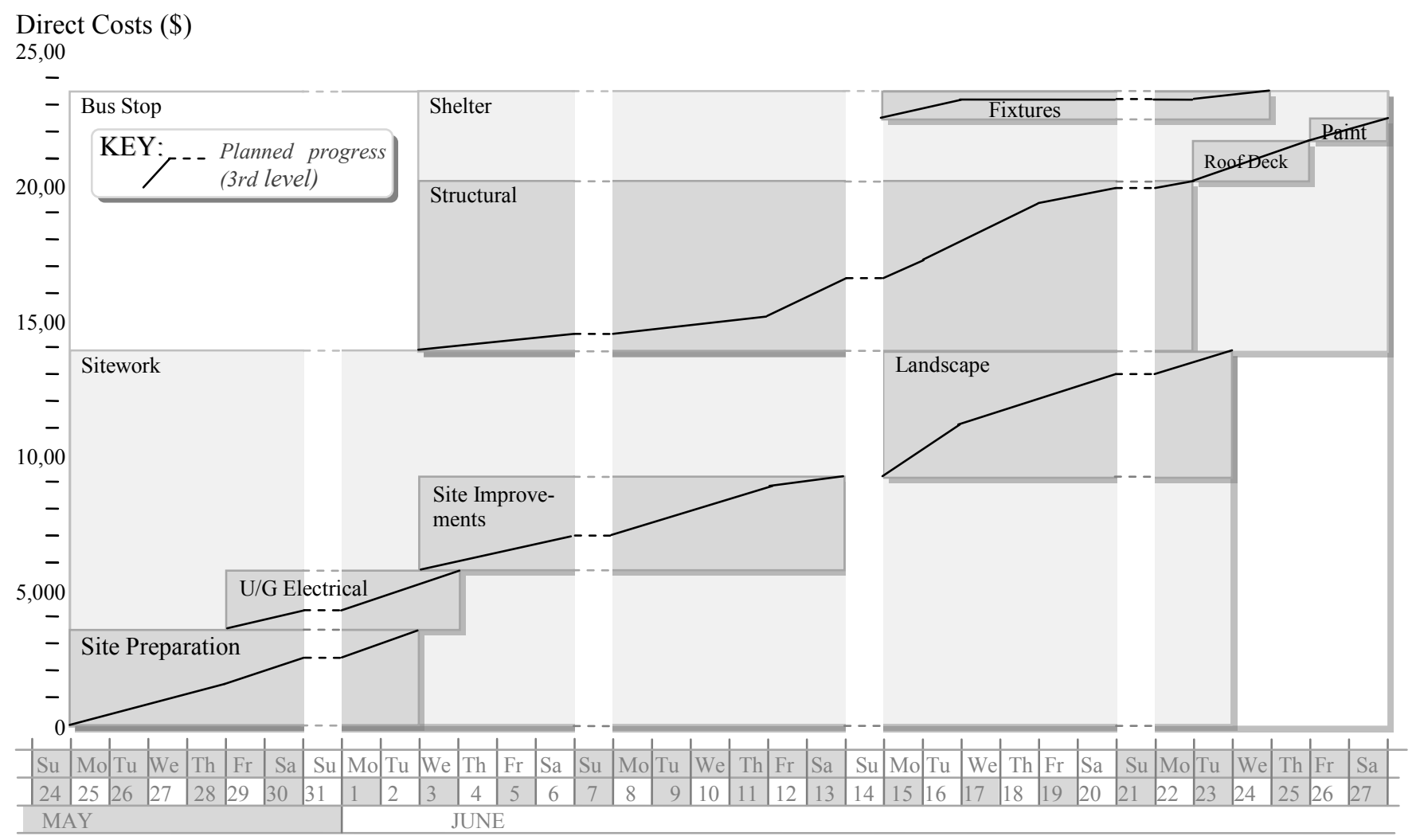

Figure 9: Bus Stop Project with Cumulative Progress Traced for the $3^{\text {rd }}$ Level Work Units

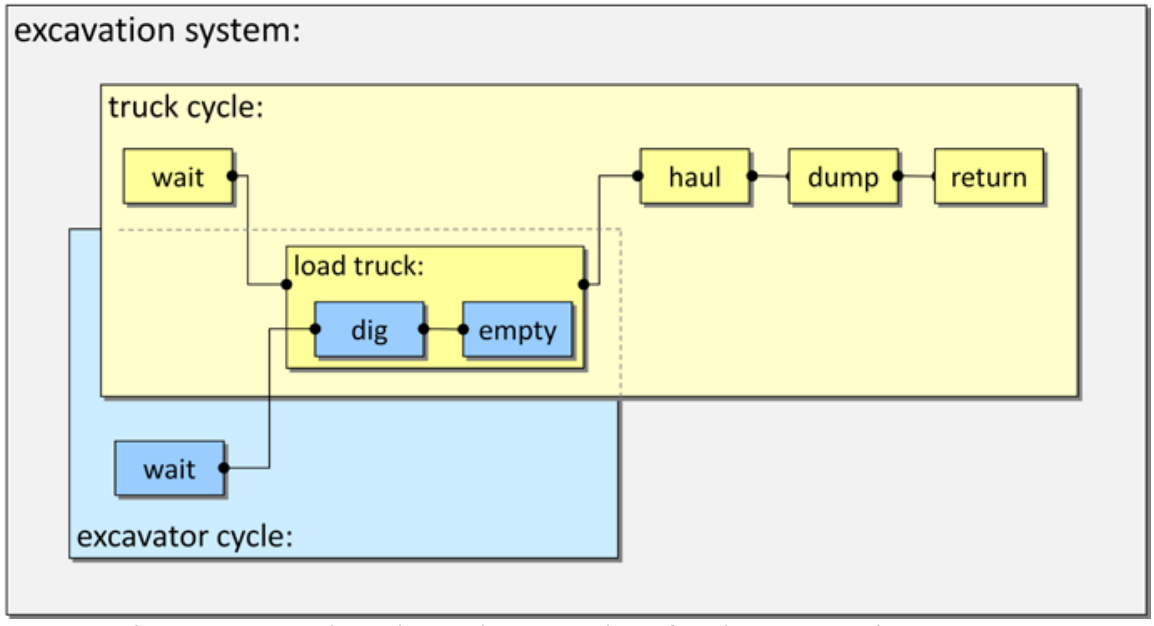

Figure 10: Work Units and Constraints for the Excavation System 


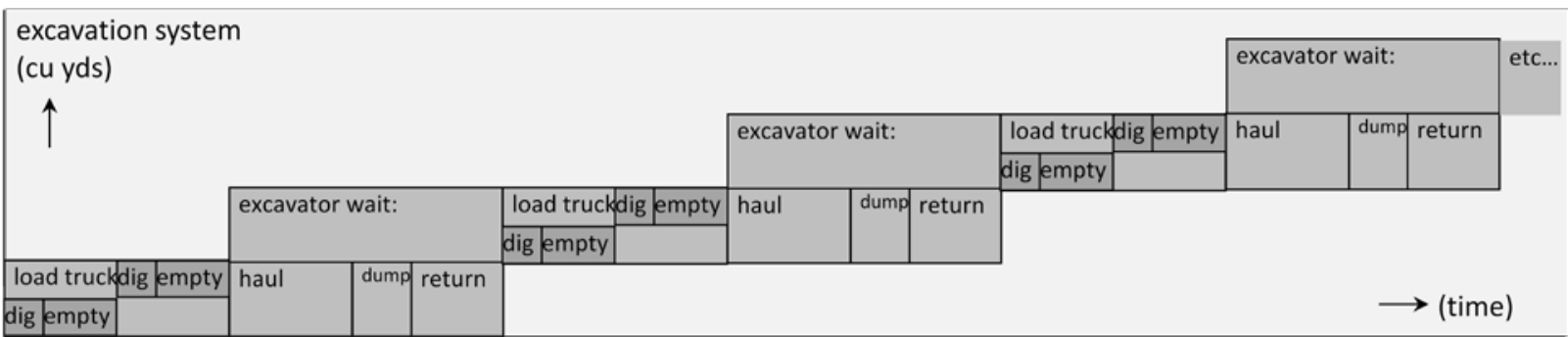

(a) Work Units with the Constraints Resolved

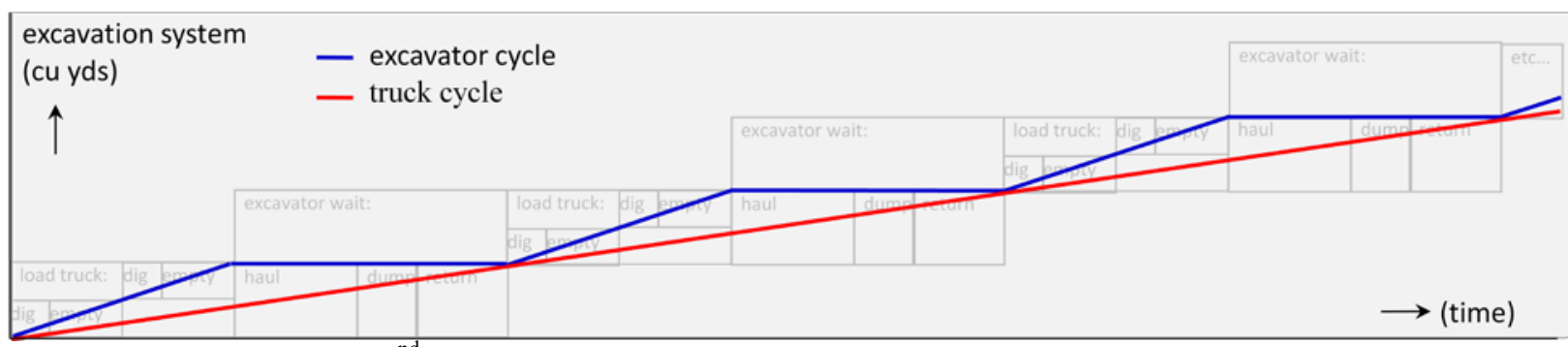

(b) Progress Traced for the $2^{\text {nd }}$ Level Work Units

Figure 11: Work Progress for the Excavation System

Figure 11(a) shows the model as it exists in the time and $c u-y d s$ of dirt excavated dimensions, with all constraints resolved for the first three truck loads. The progress of the model would actually continue until some overall constraint was reached such as a limit on the amount of dirt to be excavated. Figure 11(b) shows the same model but with progress curves plotted for the second level work units: Truck cycle and Excavator cycle. Inspection of both parts of this figure suggests that the time spent by the excavator in an idle state (waiting for the truck to return) could be removed by the addition of one truck. The addition of additional trucks can be implemented simply by allowing the work unit Truck cycle to be replicated concurrently (that is, with more than one at any time) and to constrain this to the number of available trucks.

\section{CONCLUSIONS}

The paper has proposed a new approach for modeling construction processes built on concepts pertinent to contemporary project planning. The principles upon which the approach is based provide it with the versatility necessary to model the broad spectrum of construction projects that until now have required the use of several different modeling tools. The resultant models are highly visual in form, representing the progress of work within the model structure. This provides insight into how the design of a process will impact its performance. The new approach also recognizes the need to facilitate planning of large complicated projects, achieving this by means of a hierarchical structuring of work. A final advantage of the approach is that it is easy to use and learn, being conceptually no more complicated than CPM. Indeed, a new user could use the system to produce models that are structurally exactly the same as a CPM model, and then with experience learn how to use these same functional elements in a more sophisticated way to represent a broader range of situations and to develop models that have a more insightful structure.

Research is on-going developing detailed models using this method for a variety of project types. The objective of these studies is to determine the successes and limitations of the proposed planning method in the real-world, and to determine refinements that will increase its value as a modeling tool. In particular, consideration is being given to the inclusion and representation of stochastic effects within these models.

\section{REFERENCES}

AbouRizk, S.M., Hajjar, D. 1998. “A Framework for Applying Simulation in the Construction Industry." Canadian Journal of Civil Engineering, 25(3) 604-617.

Ceric, V. 1994. "Hierarchical Abilities of Diagrammatic Representations of Discrete-Event Simulation Models." In Proceedings of the 1994 Winter Simulation Conference, ed. J.D. Tew, S. Manivannan, D. A. Sadowski, and A. F. Seila, 589-594. Piscataway, New Jersey: Institute of Electrical and Electronics Engineers. 
Flood, I., R.R.A. Issa, and W. Liu. 2006. "A New Modeling Paradigm for Computer-Based Construction Project Planning", Proc. of Joint Intnl. Conf. on Cmptg. and Decision-Making in Civil and Building Engineering, Montreal, Canada, ASCE, June 2006, 1-11.

Hajjar, D., and S.M. AbouRizk. 2002. "Unified Modeling Methodology for Construction Simulation." Journal of Construction Engineering and Management, ASCE, 128(2), 174-185.

Halpin, D.W. and R.W. Woodhead. 1976. Design of Construction and Process Operations. John Wiley and Sons, Inc., New York, NY.

Harris, R.B., and P.G. Ioannou. 1998. "Scheduling Projects with Repeating Activities." Journal of Construction Engineering and Management. ASCE, 124(4) 269-276.

Huber P., K. Jensen and R.M. Shapiro. 1990. "Hierarchies of Coloured Petri Nets." Proc. of 10th Int. Conf. on Application and Theory of Petri Nets, (LNCS 483). Springer-Verlag. 313-341.

Issa, R.A., I. Flood, and W. O'Brien, (eds.). 2003. 4D CAD and Visualization in Construction: Developments and Applications, A. A. Balkema Publishers, Steenwijk.

Koo, B., and M. Fischer. 2000. "Feasibility Study of 4D CAD in Commercial Construction." Journal of Construction Engineering and Management, ASCE, 126(4) 251-260.

Matilla, K.G., and D.M. Araham. 1998. "Linear-Scheduling: past research efforts and future directions." Engineering, Construction, and Architectural Management. Blackwell Science Ltd, 5(3) 294-303.

Sawhney, A., S.M. AbouRizk, and D.W. Halpin. 1998. "Construction Project Simulation using CYCLONE.”, Canadian Journal of Civil Engineering, 25(1), 16-25.

\section{AUTHOR BIOGRAPHY}

IAN FLOOD is an Associate Professor in the Rinker School, College of Design, Construction and Planning at the University of Florida. He received his Ph.D. from the University of Manchester, UK, on parallel computing techniques applied to the simulation of construction processes. He serves as a Specialty Editor for both the Journal of Computing in Civil Engineering, ASCE, and the Journal of Advanced Engineering Informatics, Elsevier. He has published over 120 refereed articles on the subjects of simulation modeling and intelligent computing applied to civil engineering. His email is $\langle\mathrm{fl} l o \mathrm{deufl}$. edu $>$. 